\title{
Modeling the spatial autocorrelation of pelagic fish abundance
}

\author{
Kristin M. Kleisner ${ }^{1,4, *}$, John F. Walter III $^{2}$, Sandra L. Diamond ${ }^{3}$, David J. Die ${ }^{1}$ \\ ${ }^{1}$ Rosenstiel School of Marine and Atmospheric Science, University of Miami, 4600 Rickenbacker Causeway, Miami, \\ Florida 33149, USA \\ ${ }^{2}$ Southeast Fishery Science Center, NOAA, 75 Virginia Beach Drive, Miami, Florida 33149, USA \\ ${ }^{3}$ School of Natural Sciences, University of Western Sydney, Locked Bag 1797, Penrith South DC, New South Wales 1797, \\ Australia \\ ${ }^{4}$ Present address: Fisheries Centre, University of British Columbia, 2202 Main Mall, Vancouver, British Columbia V6T 1Z4, \\ Canada
}

\begin{abstract}
The relationship between pelagic fish and ocean temperature is cited in many studies, the majority of which investigate correlations of pelagic species and sea surface temperatures (SST). While appropriate for surface-associated species, this may not be accurate for deep-diving fishes. A different way to examine this relationship is to model spatial autocorrelation of fish species and temperatures at an appropriate range of depths. Spatial autocorrelation, the distance at which data are interdependent, is a potential descriptor of the patch size of an organism. Here we modeled spatial autocorrelation for 5 pelagic species that inhabit different depths in the Gulf of Mexico: dolphinfish Coryphaena hippurus, wahoo Acanthocybium solandri, yellowfin tuna Thunnus albacares, swordfish Xiphias gladius, and bigeye tuna Thunnus obesus. Additionally, we modeled spatial autocorrelation for ocean temperatures at the surface, at 200, and $400 \mathrm{~m}$. We hypothesized that autocorrelation distances will be greater for deeper water temperatures and for species that live at deeper depths due to greater homogeneity of deep waters over greater spatial ranges. Results show average distances of autocorrelation on the order of 55 to $60 \mathrm{~km}$ for wahoo and dolphinfish, $90 \mathrm{~km}$ for yellowfin tuna, and 135 to $145 \mathrm{~km}$ for swordfish and bigeye tuna; the same data for temperature were 75, 135, and $300 \mathrm{~km}$ for SST, and at 200 and $400 \mathrm{~m}$ depth, respectively. Autocorrelation distances of dolphinfish, wahoo, and yellowfin were correlated with that of of SST, while the autocorrelation distance of swordfish and bigeye were correlated with that of temperatures at $200 \mathrm{~m}$. Results suggest that autocorrelation distances may be useful as a proxy for habitat delineation.
\end{abstract}

KEY WORDS: Spatial analysis · Geostatistics · Variogram · Pelagic habitat $\cdot$ Dolphinfish $\cdot$ Bigeye tuna Yellowfin tuna $\cdot$ Wahoo $\cdot$ Swordfish

\section{INTRODUCTION}

The biosphere is composed of many 'patchy' ecosystems related to spatially-structured biological and environmental phenomena. Our ability to quantify spatial structure lies in the degree to which spatial autocorrelation, the increased similarity of variables at shorter distances (Legendre 1993), is present in these systems. Although most ecological phenomena display spatial autocorrelation, ecological studies have traditionally taken a non-spatial perspective (Legendre \& Fortin 1989). Recently, ecologists have begun to emphasize the degree to which organisms are influenced by spatial patterns in the environment (Liebhold \& Gurevitch 2002, Giannoulaki et al. 2003).

There are 2 main approaches to dealing with spatial autocorrelation. The first is to remove spatial autocorrelation from consideration through random allocation 
of treatments to plots (Fisher 1926), i.e. random sample selection (Cochran 1977, Thompson 2002). This approach is suitable if one has the luxury of a random sampling design. When this can not be achieved, the alternative approach is to use a model to describe the spatial autocorrelation of the process of interest, and then use the model to make predictions at unsampled locations (Matheron 1971, 1973). The model-based approach is useful for situations where the spatial autocorrelation of the process itself has ecological importance (Bez 2002) as certain parameters of the spatial model can reveal spatial patterns (i.e. patch size of an organism or spatial extent of suitable habitat), which reflect the biology of the species (Freire et al. 1992, Rossi et al. 1992).

This study focuses on large pelagic fishes such as tuna and billfish whose role as apex predators is critical to the structure and function of the pelagic ecosystem. The range of movement of these species in both the vertical and horizontal spatial dimensions can vary greatly. Many of the large pelagic species are circumglobal in distribution and highly migratory, and some, like bluefin tuna Thunnus thynnus and blue marlin Makaira nigricans, exhibit transoceanic movements (Block et al. 2001, Orbesen et al. 2008). Some pelagic fish species such as sailfish Istiophorus platypterus choose a specific depth range (0 to $60 \mathrm{~m}$ ) as preferred habitat (Hoolihan \& Luo 2007), while others such as yellowfin tuna Thunnus albacares exhibit a diel pattern in depth distribution, diving to deeper waters during the day and remaining above the thermocline at night (Weng et al. 2009).

Most fish populations, including pelagic fishes, exhibit positive spatial autocorrelation, not only because fish often form schools but also because the environmental features that serve to aggregate or structure fish distributions are also spatially autocorrelated (Schneider 1989, Petitgas et al. 2001, Nishida \& Chen 2004). The idea that regional oceanographic features may define pelagic habitat is particularly important because there are no permanent structures in the pelagic realm, only transitory water conditions that may define habitat patches. Temperature is highly correlated with pelagic fish distributions, with fish aggregating along temperature fronts or within a particular temperature zone (Fiedler \& Bernard 1987, Block et al. 2001, Chen et al. 2005, Prince \& Goodyear 2006, Loefer et al. 2007). Since water characteristics at depth are generally more homogeneous than at the surface (Cummins et al. 1990, Weaver \& Sarachik 1990), temperature isobaths will likely occur over a greater horizontal distance at depth than at the surface. One implication is that a species at the surface may be subject to greater partitioning of suitable habitat than a species that spends more time in deeper waters. Therefore, one might expect smaller patches of organisms at the surface than at depth.

In this paper, we explore the spatial autocorrelation of marine pelagic species and ocean temperatures relative to depth. The objectives of this work are (1) to determine differences in the spatial autocorrelation of a suite of pelagic fish species that occupy different vertical habitats as well as differences in spatial autocorrelation of water temperature at increasing depths, and (2) to determine what relationships exist in the patterns of spatial autocorrelation within species and between species and temperature at depth. We hypothesize that (1) due to greater homogeneity of ocean waters at depth, the distance at which species are spatially autocorrelated will be greater for deeperdwelling species; (2) similarly, the distance of autocorrelation of water temperature measurements will increase with increasing depth.

\section{MATERIALS AND METHODS}

Study area. The Gulf of Mexico (GOM) is a semienclosed sea that is connected in the east to the Atlantic Ocean through the Straits of Florida, and in the south to the Caribbean Sea through the Yucatan Channel (Fig. 1). The dominant oceanographic feature in this region is the Loop Current, which enters the GOM from the Yucatan Channel and forms the beginning of the Gulf Stream. The Loop Current and the large anticyclonic rings that it sheds strongly influence the spatial structure of the biota in the GOM (Olson 2002).

Description of data. Logbook catch data (1987 to 2005) from the GOM reported by commercial US longline vessel captains for each set throughout the entire year (Beerkircher et al. 2003) were used in this study. Most of the longline fleet sets their gear in the northeastern Gulf along Loop Current fronts or associated rings. Most surface longlines in the GOM are up to $30 \mathrm{~km}$ long and typically fish between 50 and $300 \mathrm{~m}$ below the surface with an average of 1000 hooks per set (Kerstetter 2005). The coordinates of the start of the sets are expressed as degrees latitude and longitude, and for this analysis they were projected to an Albers equidistant coordinate system using ArcGIS version 9.

We used data from the 5 species most commonly encountered by commercial longlines in the GOM for the analysis. Dolphinfish Coryphaena hippurus and wahoo Acanthocybium solanderi are strictly epipelagic species (Ward \& Myers 2005, Hammond 2006). Yellowfin tuna moves between epipelagic and deep waters (Holland et al. 1990, Brill et al. 1999). Swordfish Xiphias gladius and bigeye tuna Thunnus obesus are deep-dwelling (Musyl et al. 2003, Fritsches et al. 2005). 


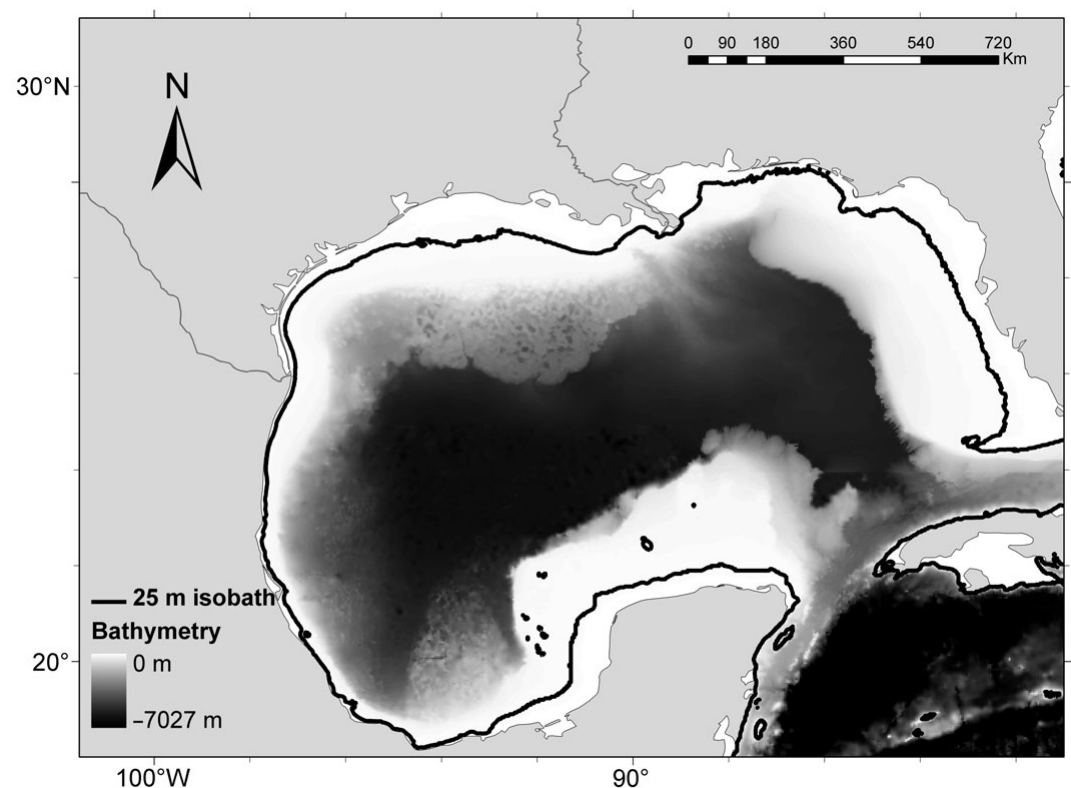

Fig. 1. Bathymetry map of the Gulf of Mexico study area showing the $25 \mathrm{~m}$ isobath. Shading is from light (shallow water) to dark (deep water)

The longline fleet in the GOM typically targets swordfish and yellowfin tuna, with dolphinfish, wahoo, and bigeye tuna considered bycatch or secondary targets. Absence (0) or presence (1) of the species divided by the number of hooks per set was the dependent variable for analysis (as opposed to abundance) because this variable is a more robust estimator when there is a high proportion of zeros in the data (Joseph et al. 2006, Bates et al. 2007). To avoid trends from gear modifications that attract fish to the longline, we constructed multiple regression models of species presence/ absence versus number of light sticks and bait type. We constructed variograms from the residuals from these regressions.

Measurements of sea surface temperature (SST) for 1987 to 2005 from in situ longline shipboard observations and temperature measurements at depths of 200 and $400 \mathrm{~m}$ from expendable bathythermograph (XBT) casts for 1987 to 1996 and 1998 to 1999 were used to determine spatial autocorrelation of habitat features. SST from the longline vessels have the same spatial location information as the catch data and were electronically recorded onboard in most cases or by digital thermometer (rated to $\pm 0.25^{\circ} \mathrm{C}$ ). There were 6143 independent XBT casts for the GOM accessed from the National Oceanographic Data Center (NODC) website. Details of the a priori processing of this data are published in the World Ocean Database literature (Locarnini et al. 2006).

Data analysis. The empirical variogram is a theoretical function that describes how data are correlated in space (Cliff \& Ord 1973, Cressie 1993, Rivoirard et al.
2000, Petitgas 2001) and is defined as the average squared difference $(h)$ between points. Often used in place of the variogram, Eq. (1) describes the empirical semi-variogram (hereafter referred to as the variogram, for brevity):

$$
\gamma(h)=\frac{1}{2|N(h)|} \sum_{N(h)}\left(Z_{X}-Z_{Y}\right)^{2}
$$

where $\gamma(h)$ is half of the variance of the variogram, $N(h)$ is the set of all pairwise Euclidian distances $h=x-y,|N(h)|$ is the number of discrete pairs in $N(h)$, and $Z_{X}$ and $Z_{Y}$ are data values at location $x$ and $y$, respectively (Goovaerts 1997). The empirical variogram is commonly plotted as the semivariance values for a given distance bin and often displays a pattern of increasing variance with increasing distance. Conversely, such a pattern indicates that spatial autocorrelation is higher at short distances and decreases as the distance between data points increases. Empirical variograms may exhibit an asymptote (or a sill) indicative of reaching a distance (often described as the range of autocorrelation) at which no autocorrelation exists, and an intercept on the $y$-axis (a nugget), indicative of finescale variability or measurement error. For kriging, a positive definite functional form parameterized by a range, nugget, and sill is often fit to the empirical variogram.

When data are aggregated over space and/or time in a geostatistical analysis, there is an increase in the smoothing of the variance of the regionalized variable as the space or time window becomes larger (Cressie 1993, Chiles \& Delfiner 1999). In theory however, the means of the smaller and larger windows should remain constant (Orasi \& Lasinio 2006). In this analysis, the temporal range varied from an individual set (i.e. daily) to the entire time series of $19 \mathrm{yr}$. Due to minimum data requirements of the variograms, the smallest time window that could be used for the species variograms was a season. However, because no significant differences between seasonal variogram parameters were found (Kleisner et al. 2007, Kleisner 2008), variograms were constructed for all sets within a year.

We defined several parameters for the calculation of the variograms. First, the maximum distance of analysis (the point at which the number of pairs of points begins to decline), was defined as $400 \mathrm{~km}$. Second, a distance bin (or lag) of $30 \mathrm{~km}$ was chosen because the length of the longlines in the GOM averaged 20 to $30 \mathrm{~km}$, and the desire was to include the majority of the short-range spatial autocorrelation. Variograms were 
estimated using variofit and the robust variogram estimator in R, which is part of the geoR package (Ribeiro Jr. \& Diggle 2001), as this method has the advantage of reducing the effect of outliers (Cressie \& Hawkins 1980). Duplicate spatial locations exist for the longline sets due to rounding of latitude and longitude by the vessel captains; therefore, the locations were randomly jittered by a small amount so no data points overlapped within a given year (R Development Core Team 2008). Theoretical spherical variograms were fit using a minimized weighted least-squares approach (Cressie 1993). We chose a spherical model, which is commonly used in geostatistical analysis of biological populations (Freire et al. 1992), because its structure of linear increase at the origin, followed by stabilization to an asymptote, corresponds with spatial variation that is often observed in nature (Lloyd 2006).

The autocorrelation distances or ranges, the sills, and the nuggets of each of the variograms were used as the dependent variables in separate ANOVA tests (henceforth referred to as the range ANOVA, sill ANOVA, and nugget ANOVA). Post hoc analyses using the Ryan-Einot-Gabriel-Welsch multiple range test (REGWQ) were used for multiple comparisons of means and to rank groups (Oehlert 2000). Means differing by more than the calculated REGWQ value were considered significantly different at a significance level of 0.05. Statistical Analysis System (SAS) for Windows (release 9.1) was used for statistical analyses.

\section{RESULTS}

For the logbook data, the number of sets in a year averaged 3389 and ranged from 2330 to 5136 (Table 1). Species variograms showed generally strong patterns of spatial autocorrelation (Figs. 2a-e). The shortest autocorrelation distance was for wahoo at $10.7 \mathrm{~km}$. Dolphinfish and wahoo were the only species whose ranges of autocorrelation were $<100 \mathrm{~km}$ in every year. Yellowfin tuna had an average autocorrelation distance of $92.2 \mathrm{~km}$ with a range of 40.7 to $149.5 \mathrm{~km}$. Swordfish and bigeye tuna had the longest average autocorrelation distances at $133.3 \mathrm{~km}(\mathrm{~min}=59.5$ and $\max =308.9 \mathrm{~km})$ and $140.6 \mathrm{~km}(\min =52.6$ and $\max =$ $362.7 \mathrm{~km}$ ), respectively. The standard deviation of the nuggets, sills, and autocorrelation distances were lowest for the dolphinfish variograms. Bigeye tuna had the highest standard deviations for the nuggets, sills and autocorrelation distances.

The average autocorrelation distance of the SST variograms was $72.4 \mathrm{~km}$ with a range similar to the yellowfin tuna variograms of 43.3 to $127.6 \mathrm{~km}$ (Fig. 2f). The average autocorrelation distance of the $200 \mathrm{~m}$ XBT variograms was $143.3 \mathrm{~km}$ with a range of 82.1 to $237.1 \mathrm{~km}$ (Fig. 3). The $400 \mathrm{~m}$ XBT variogram autocorrelation distances were significantly higher with an average of $301.6 \mathrm{~km}$, ranging from 226.0 to $377.9 \mathrm{~km}$ (Fig. 3). The standard deviation of the range parameter was highest for the $400 \mathrm{~m} \mathrm{XBT}$ and lowest for SST. The nugget stan-

Table 1. Parameters for species variogram models. N: nugget, S: sill, and R: range; ave.: average

\begin{tabular}{|c|c|c|c|c|c|c|c|c|c|c|c|c|c|c|c|c|}
\hline \multirow[t]{2}{*}{ Year } & \multirow[t]{2}{*}{ Records } & \multicolumn{3}{|c|}{ — Wahoo- } & \multicolumn{3}{|c|}{ —Dolphinfish — } & \multicolumn{3}{|c|}{ —Yellowfin tuna- } & \multicolumn{3}{|c|}{- Swordfish -} & \multicolumn{3}{|c|}{ — Bigeye tuna- } \\
\hline & & $\mathrm{N}$ & $\mathrm{S}$ & $\mathrm{R}$ & $\mathrm{N}$ & $\mathrm{S}$ & $\mathrm{R}$ & $\mathrm{N}$ & $\mathrm{S}$ & $\mathrm{R}$ & $\mathrm{N}$ & $\mathrm{S}$ & $\mathrm{R}$ & $\mathrm{N}$ & $\mathrm{S}$ & $\mathrm{R}$ \\
\hline 1987 & 5136 & 0.02 & 0.04 & 10.7 & 0.03 & 0.04 & 42.5 & 0.18 & 0.12 & 101.0 & 0.19 & 0.18 & 105.0 & 0.03 & 0.01 & 200.0 \\
\hline 1988 & 4551 & 0.10 & 0.05 & 31.9 & 0.10 & 0.18 & 29.2 & 0.14 & 0.07 & 65.3 & 0.15 & 0.15 & 72.7 & 0.12 & 0.07 & 362.7 \\
\hline 1989 & 4281 & 0.10 & 0.12 & 42.9 & 0.16 & 0.11 & 69.0 & 0.20 & 0.11 & 113.0 & 0.14 & 0.14 & 136.0 & 0.26 & 0.08 & 52.6 \\
\hline 1990 & 3507 & 0.10 & 0.11 & 36.5 & 0.23 & 0.12 & 44.1 & 0.05 & 0.15 & 71.7 & 0.10 & 0.26 & 75.7 & 0.23 & 0.07 & 113.9 \\
\hline 1991 & 2917 & 0.21 & 0.11 & 74.2 & 0.25 & 0.16 & 68.8 & 0.16 & 0.16 & 40.7 & 0.22 & 0.17 & 83.2 & 0.22 & 0.04 & 193.8 \\
\hline 1992 & 2852 & 0.14 & 0.17 & 59.3 & 0.15 & 0.16 & 66.0 & 0.26 & 0.08 & 42.0 & 0.20 & 0.21 & 200.0 & 0.11 & 0.02 & 148.7 \\
\hline 1993 & 2497 & 0.03 & 0.16 & 84.1 & 0.15 & 0.12 & 33.3 & 0.00 & 0.30 & 126.0 & 0.09 & 0.29 & 163.6 & 0.13 & 0.11 & 270.6 \\
\hline 1994 & 2330 & 0.13 & 0.17 & 58.2 & 0.15 & 0.18 & 70.2 & 0.03 & 0.30 & 98.5 & 0.07 & 0.34 & 120.3 & 0.20 & 0.39 & 77.4 \\
\hline 1995 & 2718 & 0.00 & 0.35 & 88.8 & 0.05 & 0.31 & 39.7 & 0.02 & 0.27 & 127.1 & 0.01 & 0.33 & 130.9 & 0.40 & 0.22 & 91.5 \\
\hline 1996 & 3554 & 0.03 & 0.23 & 73.5 & 0.13 & 0.15 & 39.5 & 0.00 & 0.27 & 136.1 & 0.05 & 0.32 & 197.6 & 0.42 & 0.12 & 109.7 \\
\hline 1997 & 3378 & 0.10 & 0.27 & 45.6 & 0.10 & 0.16 & 44.5 & 0.08 & 0.24 & 118.7 & 0.10 & 0.25 & 157.5 & 0.42 & 0.22 & 73.7 \\
\hline 1998 & 2785 & 0.18 & 0.25 & 70.2 & 0.18 & 0.10 & 64.3 & 0.20 & 0.22 & 118.1 & 0.15 & 0.22 & 131.1 & 0.41 & 0.18 & 85.9 \\
\hline 1999 & 3267 & 0.25 & 0.13 & 44.3 & 0.14 & 0.18 & 69.2 & 0.14 & 0.12 & 54.6 & 0.26 & 0.15 & 77.4 & 0.41 & 0.17 & 82.3 \\
\hline 2000 & 3159 & 0.19 & 0.13 & 58.4 & 0.18 & 0.10 & 31.2 & 0.23 & 0.08 & 47.4 & 0.23 & 0.15 & 85.0 & 0.32 & 0.22 & 94.1 \\
\hline 2001 & 3434 & 0.15 & 0.10 & 41.0 & 0.25 & 0.10 & 53.5 & 0.15 & 0.15 & 72.9 & 0.22 & 0.14 & 59.5 & 0.38 & 0.07 & 68.7 \\
\hline 2002 & 3667 & 0.20 & 0.10 & 76.3 & 0.20 & 0.13 & 51.5 & 0.10 & 0.19 & 131.8 & 0.11 & 0.29 & 308.9 & 0.22 & 0.19 & 200.0 \\
\hline 2003 & 3830 & 0.10 & 0.14 & 32.9 & 0.15 & 0.12 & 64.2 & 0.14 & 0.17 & 65.5 & 0.20 & 0.17 & 107.3 & 0.26 & 0.16 & 149.9 \\
\hline 2004 & 3765 & 0.20 & 0.07 & 60.8 & 0.16 & 0.12 & 91.3 & 0.25 & 0.16 & 149.5 & 0.20 & 0.18 & 184.9 & 0.19 & 0.17 & 95.7 \\
\hline 2005 & 2755 & 0.16 & 0.10 & 42.2 & 0.08 & 0.08 & 71.6 & 0.26 & 0.19 & 72.6 & 0.07 & 0.29 & 135.7 & 0.41 & 0.03 & 200.0 \\
\hline Ave. & 3389 & 0.13 & 0.15 & 54.3 & 0.15 & 0.14 & 54.9 & 0.14 & 0.18 & 92.2 & 0.15 & 0.22 & 133.3 & 0.27 & 0.13 & 140.6 \\
\hline $\mathrm{SD}$ & - & 0.07 & 0.08 & 20.4 & 0.06 & 0.06 & 17.1 & 0.09 & 0.07 & 35.2 & 0.07 & 0.07 & 60.4 & 0.12 & 0.09 & 80.2 \\
\hline
\end{tabular}



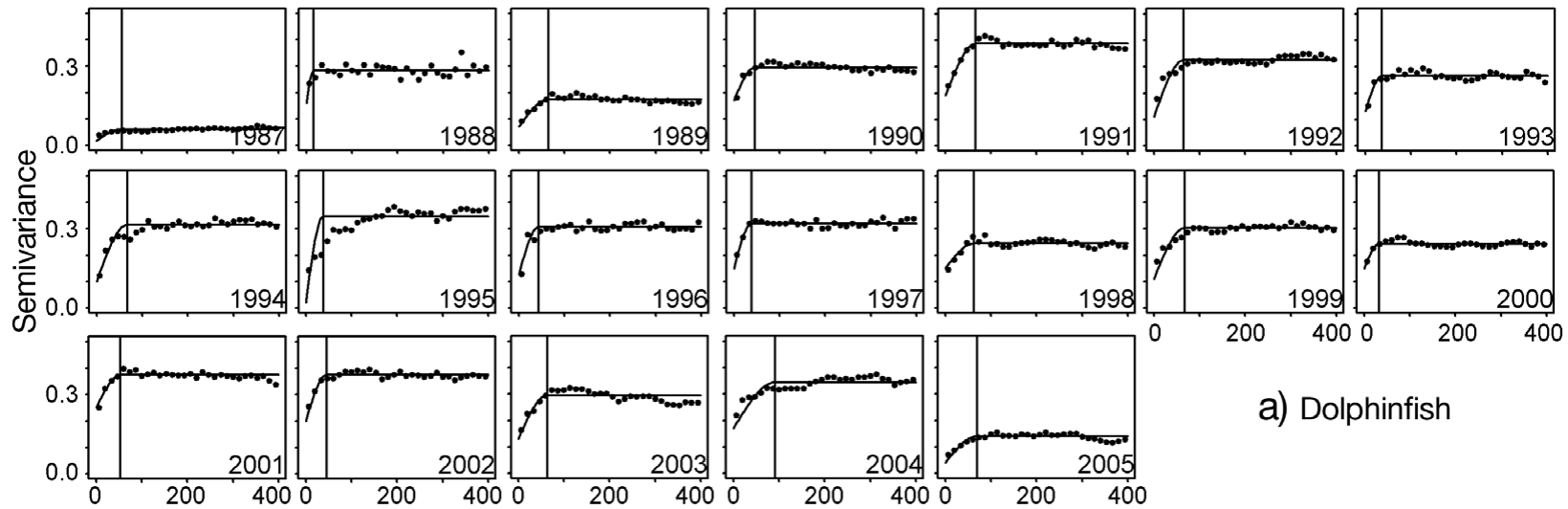

a) Dolphinfish
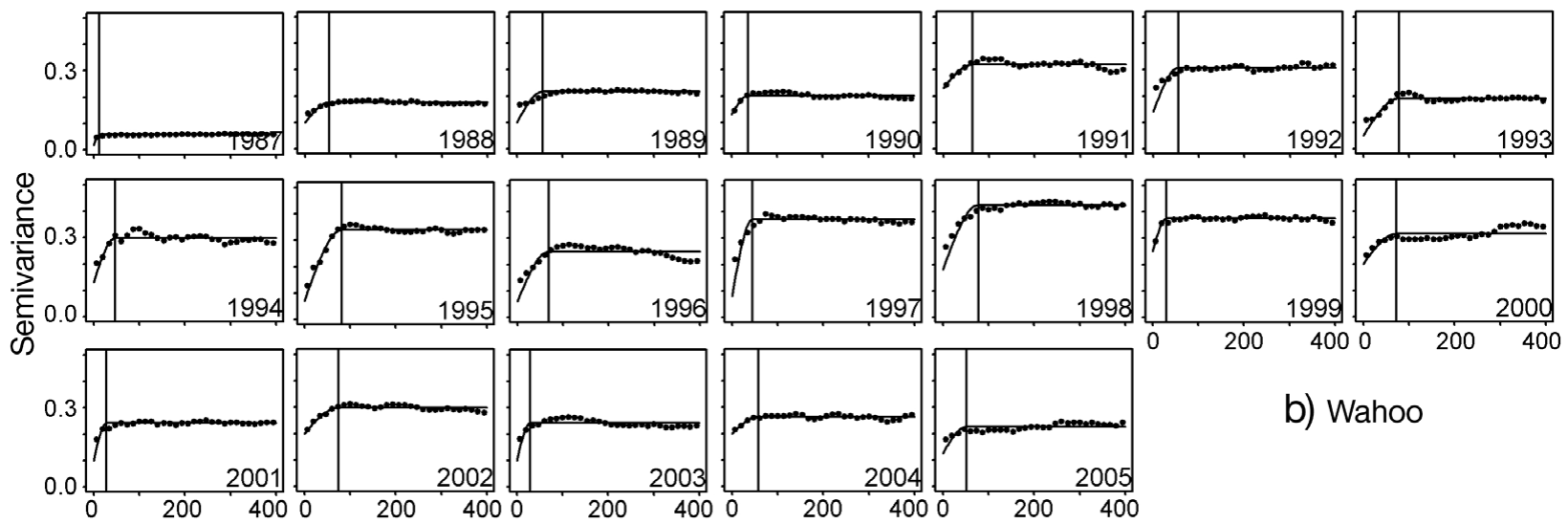

b) Wahoo
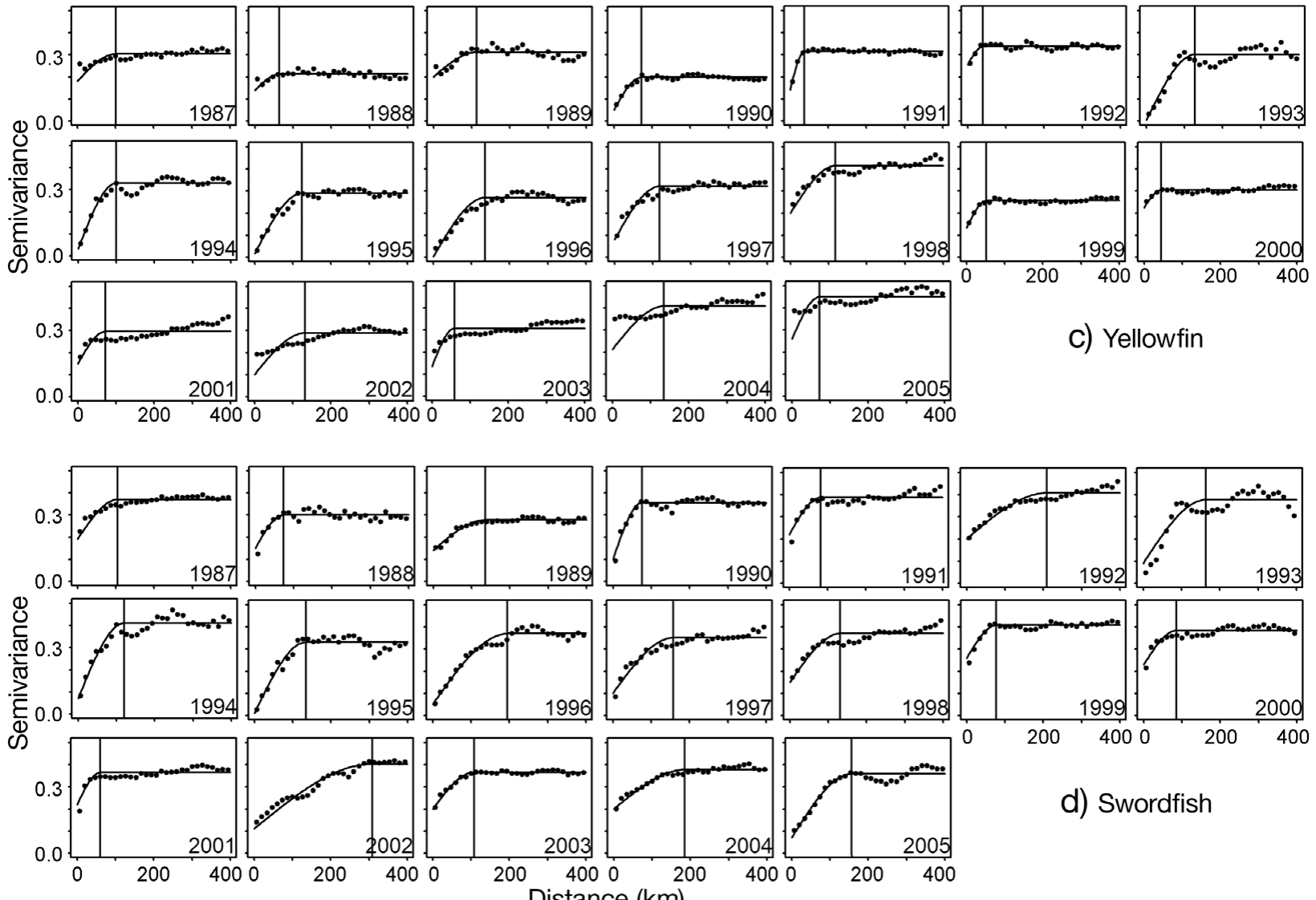

Fig. 2. (continued on the next page). Standardized annual variograms for (a) dolphinfish, (b) wahoo, (c) yellowfin tuna, (d) swordfish, (e) bigeye tuna, and (f) sea surface temperature (SST). Autocorrelation distance is listed on each graph and displayed with a 

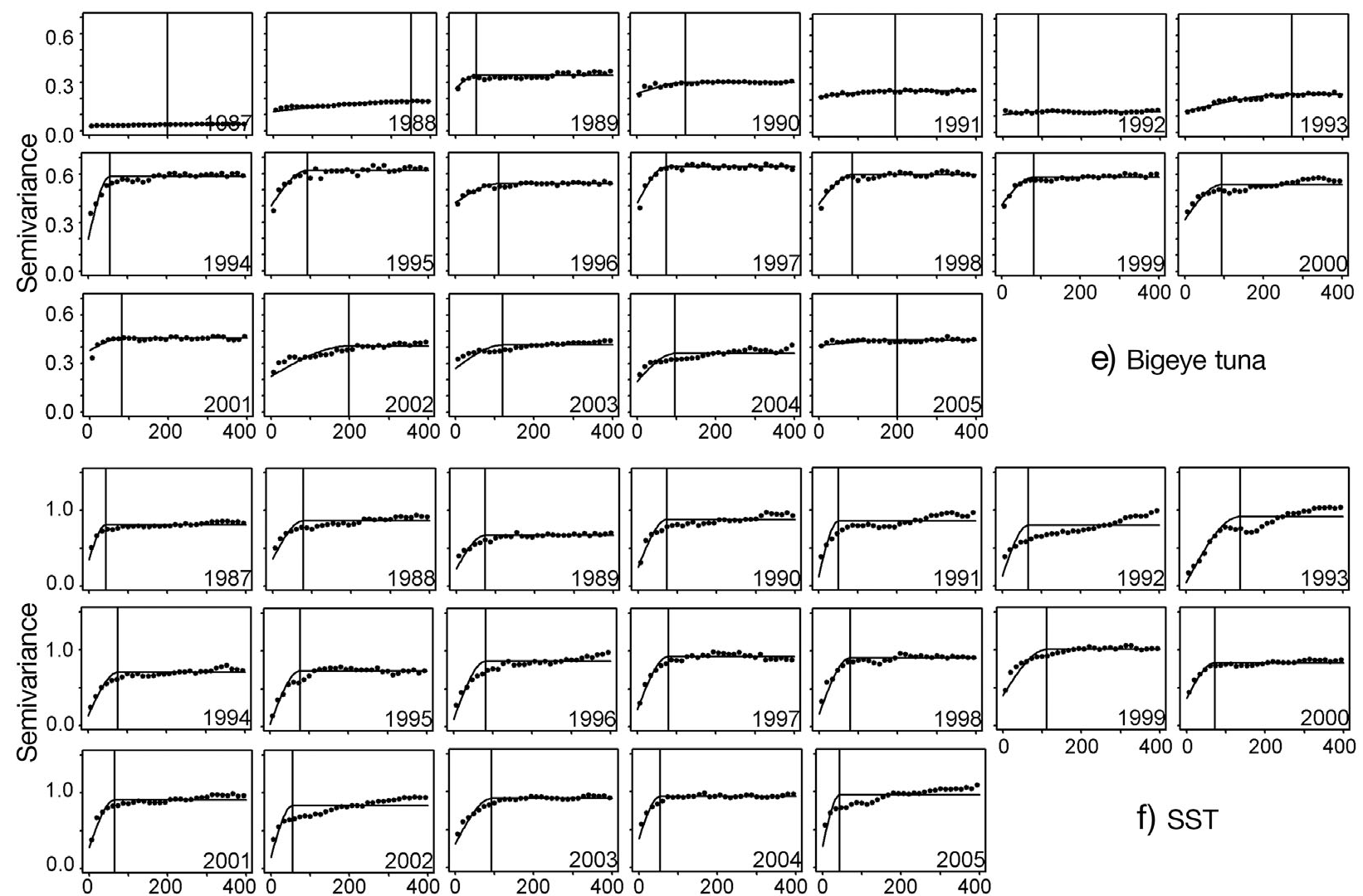

f) SST

Fig. 2 (continued)

Table 2. Parameters for temperature variograms. N: nugget, S: sill, and R: range. XBT: expendable bathythermograph. XBT casts were not available for every year. Missing years: -

\begin{tabular}{|c|c|c|c|c|c|c|c|c|c|}
\hline \multirow{2}{*}{ Year } & \multicolumn{3}{|c|}{$-\mathrm{SST}$} & \multicolumn{3}{|c|}{-XBT200- } & \multicolumn{3}{|c|}{-XBT400 } \\
\hline & $\mathrm{N}$ & $\mathrm{S}$ & $\mathrm{R}$ & $\mathrm{N}$ & $\mathrm{S}$ & $\mathrm{R}$ & $\mathrm{N}$ & $\mathrm{S}$ & $\mathrm{R}$ \\
\hline 1987 & 0.35 & 0.43 & 46.4 & 0.40 & 0.61 & 181.8 & 0.16 & 0.56 & 233.3 \\
\hline 1988 & 0.30 & 0.53 & 72.6 & 0.10 & 0.81 & 92.3 & 0.26 & 0.67 & 261.5 \\
\hline 1989 & 0.40 & 0.83 & 62.4 & 0.01 & 0.93 & 181.1 & 0.01 & 0.99 & 372.1 \\
\hline 1990 & 0.13 & 0.71 & 79.4 & 0.18 & 0.74 & 85.7 & 0.22 & 0.59 & 359.3 \\
\hline 1991 & 0.40 & 0.59 & 43.3 & 0.09 & 0.92 & 136.0 & 0.01 & 0.66 & 301.6 \\
\hline 1992 & 0.08 & 0.74 & 71.0 & 0.01 & 0.45 & 82.1 & 0.03 & 0.50 & 298.0 \\
\hline 1993 & 0.04 & 0.72 & 127.6 & 0.55 & 0.43 & 150.7 & 0.05 & 0.50 & 377.9 \\
\hline 1994 & 0.20 & 0.48 & 73.5 & 0.01 & 0.68 & 237.1 & 0.04 & 0.67 & 232.2 \\
\hline 1995 & 0.11 & 0.43 & 64.6 & 0.10 & 0.66 & 153.9 & 0.04 & 0.50 & 355.7 \\
\hline 1996 & 0.05 & 0.37 & 84.7 & 0.01 & 0.66 & 204.1 & 0.01 & 0.72 & 248.3 \\
\hline 1997 & 0.20 & 0.79 & 82.7 & - & - & - & - & - & - \\
\hline 1998 & 0.10 & 0.44 & 83.7 & 0.30 & 0.40 & 100.3 & 0.01 & 1.06 & 353.4 \\
\hline 1999 & 0.40 & 0.61 & 105.7 & 0.50 & 0.26 & 114.1 & 0.04 & 0.5 & 226.0 \\
\hline 2000 & 0.40 & 0.44 & 63.0 & - & - & - & - & - & - \\
\hline 2001 & 0.24 & 0.38 & 68.7 & - & - & - & - & - & - \\
\hline 2002 & 0.15 & 0.70 & 55.2 & - & - & - & - & - & - \\
\hline 2003 & 0.30 & 0.62 & 96.4 & - & - & - & - & - & - \\
\hline 2004 & 0.40 & 0.59 & 51.4 & - & - & - & - & - & - \\
\hline 2005 & 0.30 & 0.66 & 43.5 & - & - & - & - & - & - \\
\hline Average & 0.24 & 0.58 & 72.4 & 0.19 & 0.63 & 143.3 & 0.07 & 0.66 & 301.6 \\
\hline $\mathrm{SD}$ & 0.13 & 0.14 & 21.8 & 0.20 & 0.21 & 50.4 & 0.09 & 0.19 & 59.8 \\
\hline
\end{tabular}

dard deviations were highest for XBT at $200 \mathrm{~m}$ and lowest for XBT at $400 \mathrm{~m}$. The standard deviation of the sills was highest for XBT at $200 \mathrm{~m}$ and lowest for SST.

The range ANOVA emphasized the differences between observations of species associated with the surface and those with deep waters. Results of the range ANOVA indicated that the factors of year and species/temperature contributed to $73.7 \%$ of the variation between the range parameters from the annual variogram models. Root mean square errors (RMSEs) showed a significant difference between species/ temperature $(\mathrm{p}<0.001, \mathrm{df}=7, \mathrm{~F}=39.35)$ and no significant difference between year $(p=0.2086, d f=18, F=1.47)$ at the $5 \%$ alpha significance level using Type 3 Sum of Squares (SS). Results of the REGWQ test indicated no significant difference between the autocorrelation distances within individual temperatures or species type. However, the autocorrelation distances of swordfish, 

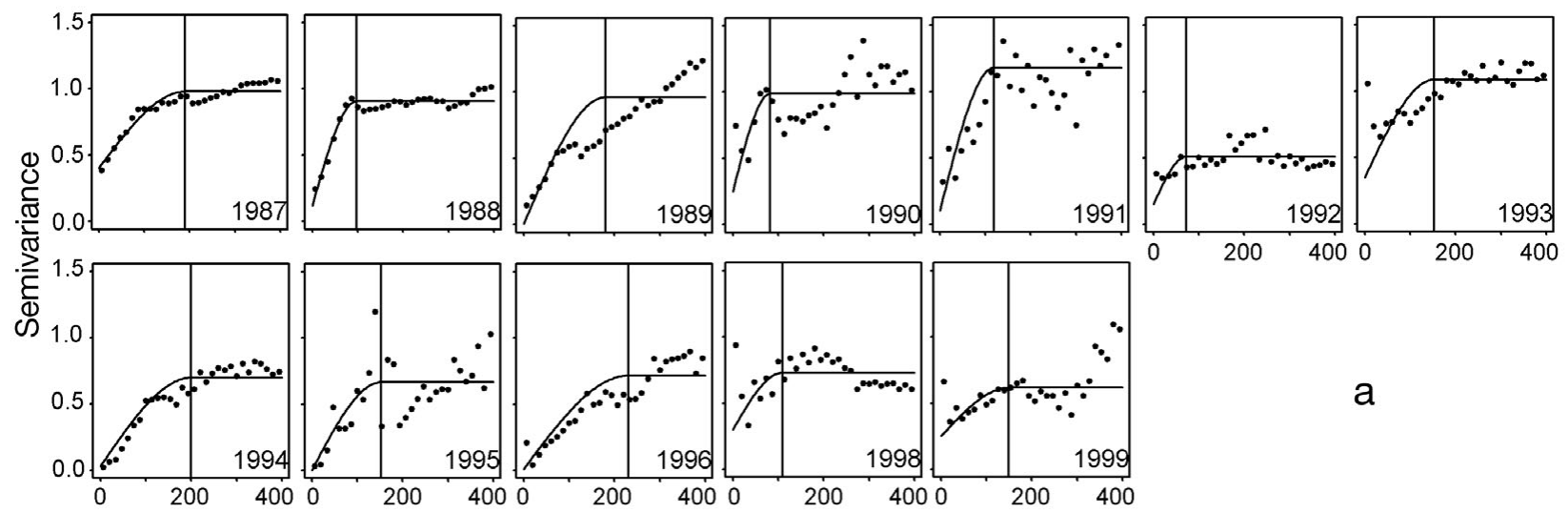

a
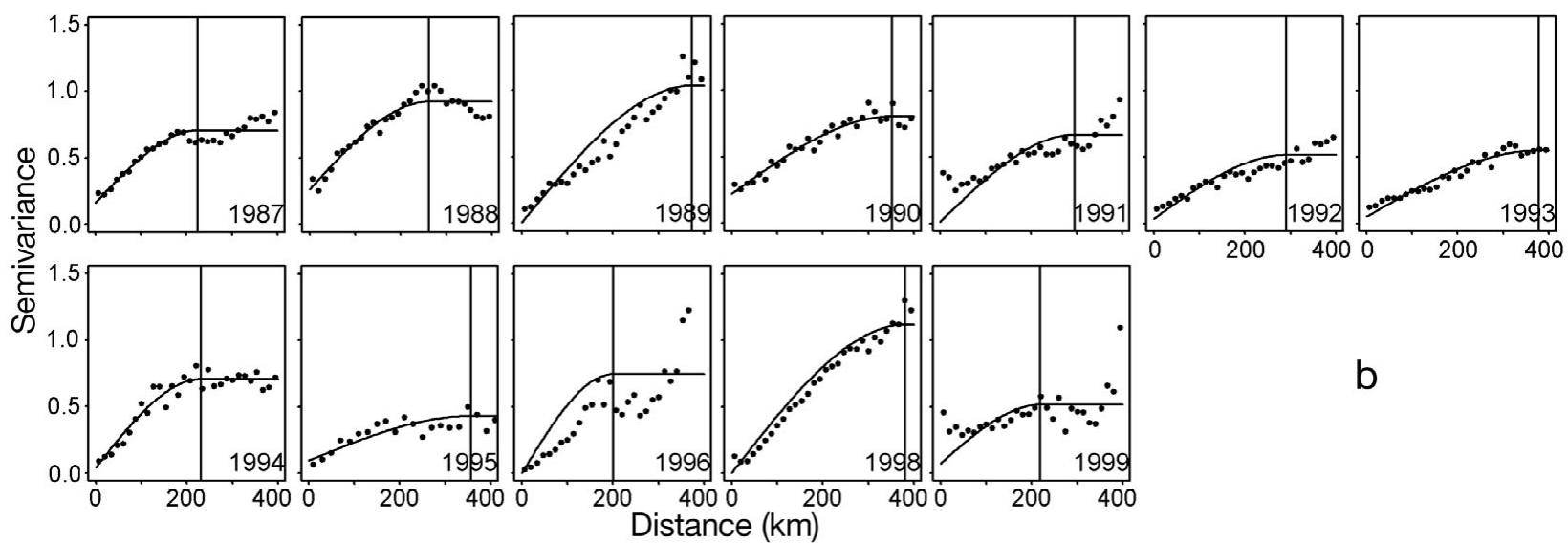

Fig. 3. Standardized annual variograms for expendable bathythermograph (XBT) casts at (a) $200 \mathrm{~m}$ (b) $400 \mathrm{~m}$. Vertical line: autocorrelation distance

bigeye tuna, and $200 \mathrm{~m}$ XBT as a group were significantly different than the autocorrelation distances of dolphinfish, wahoo, and SST as a separate group. Yellowfin tuna was a member of each of these groups. Temperature as measured by the XBT at $400 \mathrm{~m}$ was significantly different than all of the other species/ temperature groups. Fig. 4 highlights the difference between the autocorrelation distance of shallow water species and surface temperature, and between deepwater species and temperature at $200 \mathrm{~m}$. These results indicate that the autocorrelation distance increases with depth for both the catch rates of the fish and for temperature measurements. The standard deviation of the autocorrelation distances also increased with depth.

The sill ANOVA indicated that the factors of year and species/temperature contributed to $82.1 \%$ of the variation between the sill parameters from the annual variogram models. RMSEs showed a significant difference between species/temperature $(\mathrm{p}<0.001$, $\mathrm{df}=7$, $F=65.96)$ and no significant difference between year ( $p=0.1183, \mathrm{df}=18, F=1.46$ ) at the $5 \%$ alpha significance level using Type 3 SS. Results of the REGWQ test indicated no significant difference between the autocorrelation distances within individual temperatures or species type. However, the autocorrelation distances of the temperatures were significantly different than the autocorrelation distances of the species. An interesting observation with regards to the species sills was that the 2 main target species, swordfish and yellowfin tuna, had the highest sills, indicating higher variance in the catch rates of the target species.

The ANOVA for the effect of year and species on nugget indicated that the independent variables contributed to only $41.3 \%$ of the variation between the sill parameters from the annual variogram models. RMSEs showed a significant difference between species/ temperature $(\mathrm{p}<0.001, \mathrm{df}=7, F=6.20)$ and year $(\mathrm{p}=$ $0.0320, \mathrm{df}=18, F=1.81$ ) at the $5 \%$ alpha significance level using Type 3 SS. However, the REGWQ test failed to find a significant difference between any years. There were 4 significant species/temperature groupings from the REGWQ test: (1) bigeye tuna, SST, and XBT at $200 \mathrm{~m}_{i}$ (2) SST, XBT at $200 \mathrm{~m}$, dolphinfish, swordfish, and yellowfin tuna; (3) XBT at $200 \mathrm{~m}$, dolphinfish, swordfish, yellowfin tuna, and wahoo; and (4) dolphinfish, swordfish, yellowfin tuna, wahoo, and $\mathrm{XBT}$ at $400 \mathrm{~m}$. 


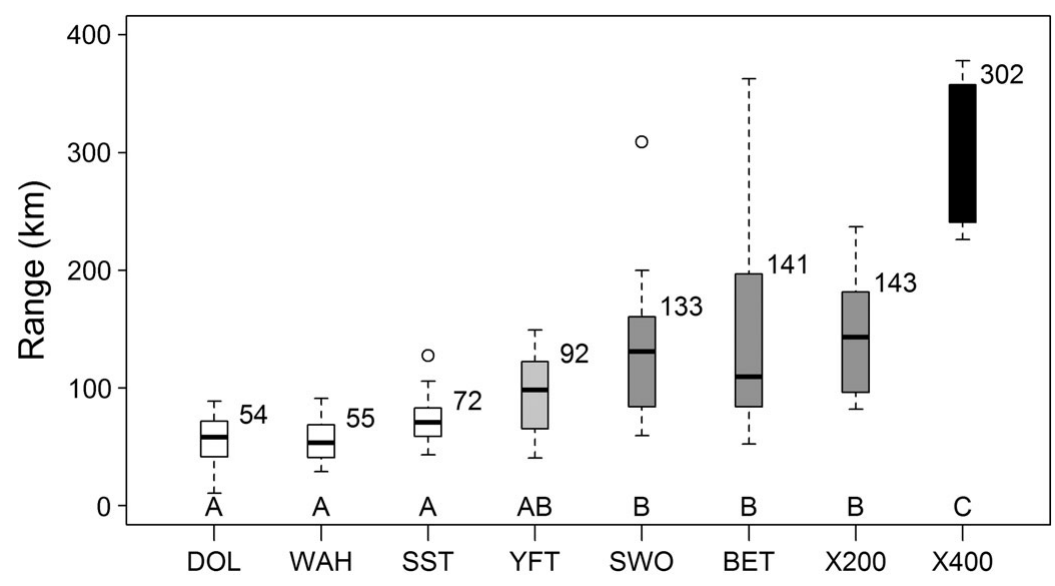

Fig. 4. Boxplot of the distribution of the range parameter from the variogram models. Medians of each group are noted by dark bars and the arithmetic mean is presented numerically. Letters reflect significant groupings by depth from the ANOVAs and post-hoc tests. DOL: dolphinfish; WAH: Wahoo; SST: sea surface temp; YFT: yellowfin tuna; SWO: swordfish; BET: bigeye tuna; X: expendable bathythermograph

\section{DISCUSSION}

Our results provide evidence for a relationship between the autocorrelation distance of temperature zones with increasing depth and the depth distribution of pelagic fishes in the GOM. The species selected for this analysis fall into an epipelagic group (dolphinfish and wahoo), an upper mesopelagic group (yellowfin tuna), and a deep mesopelagic group (swordfish and bigeye tuna). Significant differences in autocorrelation distances between species depth groups indicate that the observed spatial autocorrelation reflects biological characteristics of the species. With pelagic species, the biology and physiology of the animal is closely linked to the oceanography of the system. A significant amount of work has linked the distribution of pelagic species to temperature gradients and fronts in surface waters (Uda 1973, Laurs et al. 1984, Power \& May 1991, Andrade 2003), but few studies have explored this phenomenon with regards to depth.

In this study, the autocorrelation distances were significantly different for each species depth group. Dolphinfish and wahoo had autocorrelation distances statistically similar to SSTs. Both dolphinfish and wahoo live in shallow waters $(<50 \mathrm{~m})$ during the day and night (Hammond 2006) and have been noted to aggregate along temperature fronts and under floating debris (Castro et al. 2002). This behavior suggests a more constrained ecological niche than a species that is able to dive to deeper waters and that is less restricted to a specific temperature range. Bigeye tuna and swordfish had autocorrelation distances statistically similar to temperatures at $200 \mathrm{~m}$. These species are known to dive. Swordfish has routinely been recorded making deep dives to $500-600 \mathrm{~m}$ during the day and are found above $200 \mathrm{~m}$ in the water column during the night (Carey \& Robison 1981). Similarly, the classic bigeye tuna vertical behavior garnered from sonar tracking experiments and tagging shows the fish occupying the top $100 \mathrm{~m}$ of the water column at night and having a much deeper depth distribution during the day when they reach depths between 400 and $600 \mathrm{~m}$ (Brill et al. 2005). Some records show this species making occasional dives to depths deeper than $700 \mathrm{~m}$. Yellowfin tuna grouped with both the shallow and deep groups separately, likely related to increased vertical migration of this species through the water column.

A possible explanation for the difference between the deeper diving bigeye tuna and yellowfin tuna suggested by Brill et al. (1999) is that larger scombrids are less limited by the effects of temperature on cardiac function. Physiological studies have confirmed that yellowfin tuna are subject to more significant temperature constraints than larger tuna like bluefin or bigeye tuna (Korsmeyer et al. 1997, Freund 1999), although they are less constrained than the strictly surface-associated species. More recently, a study by Galli et al. (2009) revealed that swordfish and bigeye tuna have a specialized cardiac muscle that increases force as temperature declines (i.e. at deeper depths) and that recruits intracellular $\mathrm{Ca}^{2+}$ to support contraction and relaxation of the heart at cold temperatures. This specialization is absent in yellowfin tuna and dolphinfish and may limit the depth of foraging for these species (Galli et al. 2009). These patterns suggest that shallow-water species have increased tendencies to aggregate compared to deeper dwelling species and may be subject to greater niche partitioning.

The higher standard deviation of the autocorrelation distance of the deep-water species may reflect greater vertical movement. The general increase in the autocorrelation distances of deep temperature variograms reflects larger 'patches' of water temperature (i.e. increasing homogeneity) at depth. The fact that SST and the surface-associated species group had similar autocorrelation distances and lower standard deviations signifies that temperature and possibly temperature fronts could be the mechanism constraining the distribution of surface-dwelling species. For the species variograms, the sills reflect the variability in the catchability of the species. In general, the average sills of the target species (swordfish and yellowfin tuna) were higher than the non-target spe- 
cies. This indicates that the sill reflects the proportion of the target species in the catch. Likewise, one might expect that the sills for the temperature variograms would decrease with increasing depth as waters become more homogeneous. However, the SST variograms displayed the lowest average sill, with the highest for XBT at $200 \mathrm{~m}$, an indication that there is variability in the measurements within a year, possibly related to the spatial disjoint in the XBT and SST temperature measurements within a year. It was difficult to determine a distinct pattern from the variogram nuggets. In general, the nugget increased for deeper species. However, these differences did not reveal statistically significant patterns. The variability of the nugget indicates that small scale variability varies greatly between years.

One mechanism that may explain the observed increase in the autocorrelation distance of temperature with depth and its relationship to the spatial structure of fish populations in the GOM is the Rossby radius of deformation, which describes the homogeneity of water masses at a particular latitude and depth in the ocean. Specifically, it is the spatial distance at which rotational effects become as important as buoyancy effects in the evolution of the current flow about some disturbance (Rossby 1938). The Rossby radius emphasizes the fact that there is less oceanographic variability at depth; therefore, it is important to account for the 3-dimensional nature of both physical and ecological patches. In the surface waters, Rossby radius was calculated to be $30 \mathrm{~km}$ in the GOM (Teague et al. 1990). Due to its proportionality to depth, it increases with depth to the point where the deepest oceanic waters are a uniformly cold temperature. Therefore, a species at depth should experience a more homogeneous habitat over a greater horizontal extent than at the surface.

Ecologically, larger temperature patches at depth may have significant implications for competition, community structure, and the ability of an organism to locate prey. The diversity of pelagic species decreases with depth (Smith \& Brown 2002); therefore, competition among species should be greater at the surface. High environmental variation at the surface (Kendall \& Haedrich 2006) may not only drive aggregation of surface-associated pelagic predators, but also aggregation of prey (Olson et al. 1994). Dolphinfish and wahoo, which exhibit high growth and consumption rates (Uchiyama et al. 1986, Wild 1986, Olson \& GalvanMagana 2002), would benefit from aggregated prey that would allow hunting over shorter distances and lower expenditures of energy. Conversely, deepdiving species are adapted to hunt over long distances, in cold water and reduced light (Brill et al. 2005, Fritsches et al. 2005). Therefore, it is logical that they would have longer autocorrelation distances.
A major concern with pelagic longline data is that spatial distribution is heavily influenced by fishermen's choice of fishing location. This results in a set of samples that is not random. Geostatistical methods are, in general, more robust to non-random sampling than design-based statistical methods, but it is not known how this might affect estimation of variograms. A second concern is the fact that the exact spatial location of the catch on the longline is not known. This contributes to poor sample resolution where the position of the catch has a margin of error on the scale of the length of the longline. Despite this, the level of spatial resolution of this type of data represents a significant improvement over the aggregated $10 \times 10$ degree blocks that are often used to report data from Atlantic pelagic fisheries (ICCAT 2007). Third, the depth of catch is not available. The implications are that the patterns observed in the temperature variograms are not the only explanations for the differences in the autocorrelation distances of deep and shallow-associated species. However, in support of these patterns, depth distribution of electronically tagged, free-swimming bigeye tuna was similar to the depth at which they were captured on longlines based upon depth recorders placed near the hooks (Bach et al. 2003). Additionally, although baited hooks were set in both shallow and deep waters, bigeye tuna were only caught on deep hooks indicating that they do not modify their vertical distribution due to the presence of shallow bait on fishing gear. Another study estimated depth distributions for bigeye tuna, swordfish, yellowfin, and wahoo on longlines in the eastern Pacific, and found that wahoo was always caught with hooks shallower than $100 \mathrm{~m}$ while bigeye, swordfish and yellowfin were all caught with hooks deeper than $150 \mathrm{~m}$ (Zhu et al. 2009).

In summary, patterns of spatial autocorrelation in species presence/absence and sea temperature data can indicate important habitat preferences. Our ability to define habitat within the pelagic realm has ramifications for our understanding of the ecology and population dynamics of pelagic species. Identification and quantification of such patterns may assist ecosystembased fishery management by providing a means to help reduce unexplained variance in catch data and allow for the inclusion of habitat information in the stock assessment framework.

Acknowledgements. This work was supported by funding from the Cooperative Unit of Fisheries and Education Research (CUFER) of the Cooperative Institute for Marine and Atmospheric Studies (CIMAS) and Fisheries and the Environment (FATE). The authors thank NOAA and the Southeast Fishery Science Center for providing access to the pelagic longline data and E. Ryan for processing the World Ocean Database XBT data. 


\section{LITERATURE CITED}

Andrade HA (2003) The relationship between the skipjack tuna (Katsuwonus pelamis) fishery and seasonal temperature variability in the south-western Atlantic. Fish Oceanogr 12:10-18

Bach P, Dagorn L, Bertrand A, Josse E, Misselis C (2003) Acoustic telemetry versus monitored longline fishing for studying the vertical distribution of pelagic fish: bigeye tuna (Thunnus obesus) in French Polynesia. Fish Res 60: 281-292

Bates CR, Scott G, Tobin M, Thompson R (2007) Weighing the costs and benefits of reduced sampling resolution in biomonitoring studies: perspectives from the temperate rocky intertidal. Biol Conserv 137:617-625

Beerkircher L, Brown C, Lee D (2003) Overview of the SEFSC pelagic observer program in the Northwest Atlantic from 1992-2000. Col Vol Sci Pap ICCAT 55:331-349

Bez N (2002) Global fish abundance estimation from regular sampling: the geostatistical transitive method. Can J Fish Aquat Sci 59:1921-1931

Block B, Dewar H, Blackwell S, Williams T and others (2001) Migratory movements, depth preferences, and thermal biology of Atlantic Bluefin Tuna. Science 293:1310-1314

Brill RW, Block BA, Boggs $\mathrm{CH}$, Bigelow KA, Freund EV, Marcinek DJ (1999) Horizontal movements and depth distribution of large adult yellowfin tuna (Thunnus albacares) near the Hawaiian Islands, recorded using ultrasonic telemetry: implications for the physiological ecology of pelagic fishes. Mar Biol 133:395-408

Brill RW, Bigelow KA, Musyl MK, Fritsches KA, Warrant EJ (2005) Bigeye tuna behavior and physiology and their relevance to stock assessments and fishery biology. Col Vol Sci Pap ICCAT 57:142-161

Carey FG, Robison BH (1981) Daily patterns in the activities of swordfish, Xiphias gladius, observed by acoustic telemetry. Fish Bull 79:277-292

Castro JJ, Santiago JA, Santana-Ortega AT (2002) A general theory on fish aggregation to floating objects: an alternative to the meeting point hypothesis. Rev Fish Biol Fish 11: 255-277

Chen IC, Lee PF, Tzeng WN (2005) Distribution of albacore (Thunnus alalunga) in the Indian Ocean and its relation to environmental factors. Fish Oceanogr 14:71-80

Chiles JP, Delfiner P (1999) Geostatistics: modeling spatial uncertainty, Vol 1. Wiley, New York, NY

Cliff AD, Ord JK (1973) Spatial autocorrelation, Vol 1. Pion, London

Cochran WG (1977) Sampling techniques, Vol 1. John Wiley \& Sons, New York, NY

Cressie NAC (1993) Statistics for spatial data, Vol 1. John Wiley \& Sons, New York, NY

> Cressie NAC, Hawkins DM (1980) Robust estimation of the variogram: J Int Assoc Math Geol 12:115-125

> Cummins RF, Holloway G, Gargett AE (1990) Sensitivity of the GFDL ocean general circulation model to a parameterization of vertical diffusion. J Phys Oceanogr 20:817-830

Fiedler PC, Bernard HJ (1987) Tuna aggregation and feeding near fronts observed in satellite imagery. Cont Shelf Res 7: 871-881

Fisher RA (1926) The arrangement of field experiments. J Minist Agric Great Brit 33:503-513

Freire J, Gonzalez-Gurriaran E, Olaso I (1992) Spatial distribution of Munida intermedia and M. sarsi (Crustacea: Anomura) on the Galician Continental Shelf (NW Spain): application of geostatistical analysis. Estuar Coast Shelf Sci 35:637-647
Freund EV (1999) Comparisons of metabolic and cardiac performance in scombrid fishes: insights into the evolution of endothermy. PhD thesis, Stanford University

> Fritsches KA, Brill RW, Warrant EJ (2005) Warm eyes provide superior vision in swordfishes. Curr Biol 15:55-58

> Galli GLJ, Shiels HA, Brill RW (2009) Temperature sensitivity of cardiac function in pelagic fishes with different mobilities: yellowfin tuna (Thunnus albacares), bigeye tuna (Thunnus obesus), mahimahi (Coryphaena hippurus), and swordfish (Xiphias gladius). Physiol Biochem Zool 82: 280-290

Giannoulaki M, Machias A, Koutsikopoulos C, Haralabous J, Somarakis S, Tsimenides N (2003) Effect of coastal topography on the spatial structure of the populations of small pelagic fish. Mar Ecol Prog Ser 265:243-253

Goovaerts P (1997) Geostatistics for natural resource evaluation. Oxford University Press, New York, NY

Hammond D (2006) Pilot study to assess the usefulness of pop-off archival satellite tags to monitor temperature preference, vertical water column use, and migratory behavior by dolphin, Corypheana hippurus, off the east coast of the United States. South Carolina Department of Natural Resources Marine Resources Division, Charleston, SC

Holland KN, Brill RW, Chang RK (1990) Horizontal and vertical movements of yellowfin and bigeye tuna associated with fish aggregating devices. Fish Bull 88:493-507

> Hoolihan JP, Luo J (2007) Determining summer residence status and vertical habitat use of sailfish (Istiophorus platypterus) in the Arabian Gulf. ICES J Mar Sci 64:1791-1799

ICCAT (International Commission for the Conservation of Atlantic Tunas) (2007). ICCAT Stat Bull 36:109-128

$>$ Joseph LN, Field SA, Wilcox C, Possingham HP (2006) Presence-absence versus abundance data for monitoring threatened species. Conserv Biol 20:1679-1687

Kendall VJ, Haedrich RL (2006) Species richness in Atlantic deep-sea fishes assessed in terms of the mid-domain effect and Rapoport's rule. Deep-Sea Res I 53:506-515

Kerstetter D (2005) Description and evaluation of the United States coastal pelagic longline fishery interactions with target and non-target species in the western North Atlantic. $\mathrm{PhD}$ thesis, College of William and Mary, Williamsburg, VA

Kleisner KM (2008) A spatio-temporal analysis of dolphinfish, Coryphaena hippurus, abundance in the western Atlantic: implications for stock assessment of a data-limited pelagic resource. PhD thesis, University of Miami, FL

Kleisner KM, Sladek Nowlis J, Olson D, Die DJ (2007) An application of spatial modeling to the classification of pelagic habitat and the subsequent estimation of temporal abundance of dolphinfish, Coryphaena hippurus, in the western Atlantic. In: GIS/spatial analyses in fishery and aquatic sciences, Vol 3. Fishery-Aquatic GIS Research Group, Saitama, p 181-196

Korsmeyer KE, Lai NC, Shadwick R, Graham JB (1997) Heart rate and stroke volume contributions to cardiac output in swimming yellowfin tuna: response to exercise and temperature. J Exp Biol 200:1975-1986

> Laurs RM, Fiedler PC, Montgomery DR (1984) Albacore tuna catch distributions relative to environmental features observed from satellites. Deep-Sea Res 31:1085-1099

Legendre P (1993) Spatial autocorrelation: trouble or new paradigm? Ecology 74:1659-1673

> Legendre P, Fortin MJ (1989) Spatial pattern and ecological analysis. Vegetatio 80:107-138

> Liebhold AM, Gurevitch J (2002) Integrating the statistical analysis of spatial data in ecology. Ecography 25:553-557

Lloyd CD (2006) Local models for spatial analysis, Vol 1. CRC Press, Boca Raton, FL 
Locarnini RA, Mishonov AV, Antonov JI, Boyer TP, Garcia HE (2006) World Ocean Atlas 2005, Vol 1. US Government Printing Office, Washington, DC

Loefer J, Sedberry G, McGovern J (2007) Nocturnal depth distribution of western North Atlantic swordfish (Xiphias gladius, linnaeus, 1758) in relation to lunar illumination. Gulf Caribb Res 19:83-88

Matheron G (1971) The theory of regionalized variables and its applications, Vol 1. Ecole de mines, Fontainbleau

Matheron G (1973) The intrinsic random functions and their applications. Adv Appl Probab 5:439-468

Musyl MK, Brill RW, Boggs CH, Curran DS, Kazama TK, Seki MP (2003) Vertical movements of bigeye tuna (Thunnus obesus) associated with islands, buoys, and seamounts near the main Hawaiian Islands from archival tagging data. Fish Oceanogr 12:152-169

Nishida T, Chen D (2004) Incorporating spatial autocorrelation into the general linear model with an application to the yellowfin tuna (Thunnus albacares) longline CPUE data. Fish Res 70:265-274

Oehlert G (2000) A first course in design and analysis of experiments, Vol 1. Freeman, New York, NY

Olson DB (2002) Biophysical dynamics of ocean fronts. The Sea 12:187-218

Olson RJ, Galvan-Magana F (2002) Food habits and consumption rates of common dolphinfish (Coryphaena hippurus) in the eastern Pacific Ocean. Fish Bull 100:279-298

Olson DB, Hitchcock GL, Mariano AJ, Ashjian CJ, Peng G, Nero RW, Podesta GP (1994) Life on the edge: marine life and fronts. Oceanogr 7:52-60

Orasi A, Lasinio GJ (2006) Statistical aspects of rainfall fields in Southern Italy during a rain enhancement experiment. Environmetrics 17:777-793

Orbesen E, Hoolihan J, Serafy J, Snodgrass D, Peel E, Prince E (2008) Transboundary movement of Atlantic istiophorid billfishes among international and US domestic management areas inferred from mark-recapture. Mar Fish Rev 70:14-23

Petitgas P (2001) Geostatistics in fisheries survey design and stock assessment: models variances and applications. Fish Fish 2:231-249

Petitgas P, Carrera P, Iglesias M, Georgakarakos S, Liorzou B, Masse J (2001) On the relation between schools, clusters of schools, and abundance in pelagic fish stocks. ICES J Mar Sci 58:1150-1160

Power JH, May LN Jr (1991) Satellite observed sea-surface temperatures and yellowfin tuna catch and effort in the Gulf of Mexico. Fish Bull 89:429-439

Prince E, Goodyear C (2006) Hypoxia-based habitat compression of tropical pelagic fishes. Fish Oceanogr 15:451-464

R Development Core Team (2008) R: a language and environ-

Editorial responsibility: Konstantinos Stergiou, Thessaloniki, Greece ment for statistical computing. R Foundation for Statistical Computing, Vienna. www.R-project.org

Ribeiro PJ Jr, Diggle PJ (2001) geoR: a package for geostatistical analysis. R-News 1:15-18

Rivoirard J, Simmonds J, Foote K, Fernandes P, Bez N (2000) Geostatistics for estimating fish abundance, Vol 1. Blackwell Sciences, Oxford

Rossby CG (1938) On the mutual adjustment of pressure and velocity distributions in certain simple current systems, II. J Mar Res I 3:239-262

> Rossi RE, Mulla DJ, Journel AG, Franz EH (1992) Geostatistical tools for modeling and interpreting ecological spatial dependence. Ecol Monogr 62:277-314

Schneider D (1989) Identifying the spatial scale of densitydependent interaction of predators with schooling fish in the southern Labrador current. J Fish Biol 35:109-115

Smith KF, Brown JH (2002) Patterns of diversity, depth range and body size among pelagic fishes along a gradient of depth. Glob Ecol Biogeogr 11:313-322

> Teague WJ, Carron MJ, Hogan PJ (1990) A comparison between the generalized digital environmental model and Levitus climatologies. J Geophys Res 95:7167-7183

Thompson SK (2002) Sampling, Vol 1. John Wiley \& Sons, New York, NY

Uchiyama JH, Burch RK, Kraul SA Jr (1986) Growth of dolphins, Coryphaena hippurus and C. equiselis, in Hawaiian waters as determined by daily increments on otoliths. Fish Bull 84:186-191

Uda M (1973) Pulsative fluctuation of oceanic fronts in association with tuna fishing grounds and fisheries. J Fac Mar Sci Technol 7:245-265

> Ward P, Myers RA (2005) Inferring the depth distribution of catchability for pelagic fishes and correcting for variations in the depth of longline fishing gear. Can J Fish Aquat Sci 62:1130-1142

- Weaver AJ, Sarachik ES (1990) On the importance of vertical resolution in certain ocean general circulation models. J Phys Oceanogr 20:600-609

Weng KC, Stokesbury MJW, Boustany AM, Seitz AC, Teo SLH, Miller SK, Block BA (2009) Habitat and behaviour of yellowfin tuna Thunnus albacares in the Gulf of Mexico determined using pop-up satellite archival tags. J Fish Biol 74:1434-1449

Wild A (1986) Growth of yellowfin tuna, Thunnus albacares, in the eastern Pacific Ocean based on otolith increments. Bull I-ATCC (Inter-American Tropical Tuna Commission) 18:421-482

Zhu J, Xu L, Dai X, Chen X, Yong C (2009) Vertical distribution of 17 pelagic fish species in the longline fisheries in the eastern Pacific Ocean. 10th Stock Assessment Review Meeting. Inter-American Tropical Tuna Commission, La Jolla, CA

Submitted: May 20, 2009 Accepted: May 13, 2010

Proofs received from author(s): July 21, 2010 